\title{
Design of a Computer Aided Quick- Stop Device for Study of Dead Metal Zone Formation
}

Department of Mechanical Engineering

14030 Bolu, Turkey

Erhan Altan

ealtan@yildiz.edu.tr

Yıldız Technical University

Department of Mechanical Engineering

34339 Istanbul, Turkey

The use of quick-stop device allows observing a sequence of frozen images focused on the chip formation area when machining in orthogonal turning tests. This work records the development of a quick-stop device employing a servo motor. The present invention relates generally to a quick stop device, for combination with a cutting machine that is able to abruptly interrupt the cutting process between a cutting tool and the surface being cut. A dead metal zone is clearly seen when using rounded-edge cutting tools. In this study, variation of the dead metal zone is examined with the computer aided quick-stop device (CAQSD). It is clear from the experimental photomicrographs that as the cutting edge radius increases, dead metal zone increases.

Keywords: dead region, rounded-edge tool, computer aided quick-stop device

\section{Introduction}

Formation of the dead metal zone plays an important role in machining. In the cutting with edge radiused tools, a small dead metal region is seen in front of the rake face of the tool. In ultraprecision or micro machining, because the depths of cut are smaller than the tool edge radius, all these applications show the importance of the understanding of cutting mechanism with edge radiused cutting tools. The nature of tool-chip interaction in machining condition needs quick freezing of the machining action. The fundamental idea of this method is that the tool is retracted rapidly from the workpiece thereby "freezing" the process. To study the dead metal zone formation experimentally, a so called quick stop device (QSD) has been constructed. In the past, quick-stop devices have been developed and used for close study of chip-tool interactions. Quick stop devices (QSD) are a research instrument developed for investigating the plastic deformation in the workpiece material and on the surface between tool and chip. The cutting action is stopped suddenly by reducing the relative velocity between cutting tool and workpiece to zero, leaving a frozen chip attached to the workpiece. The use of QSDs allows extracting the chip root as it strains in the real process, but there exists a tool-chip separation delay which is dependent on the design of the employed QSD.

Quick-stop mechanism designed by Buda (1972) allows to break the chip root instantly. A series of notches along the sample edges initiate the severance of the chip from the workpiece. By this way, the material removal process is effectively frozen in time and the chipworkpiece interface can be sectioned for detailed examination. Komanduri (1971) conducted experiments at a fixed uncut chip thickness with varying rake angles and depth of cut. Cutting tests were performed by varying speed from 183 to $548 \mathrm{~m} / \mathrm{min}$. He limited the speeds to prevent wear of the tool. The speeds were lower than the speeds normally used in cutting. However, Komanduri (1971) raveled that chip formation mechanism was similar to that in high speed cutting. According to Jaspers and Dautzenberg (2002), at a cutting speed of $4 \mathrm{~m} / \mathrm{s}$, the tool travels approximately $13.3 \mu \mathrm{m}$ through the workpiece material during retraction. This QSD is thus considerably improved but the process remains, however, not instantaneous.

Chern (2005) developed a QSD for the study of chip formation without employing any explosive charges or breaking any shear pins. The aim declared was to study the chip morphology by considering working parameters and physical properties of the machined material.

Paper received 11 August 2011. Paper accepted 29 March 2012 Technical Editor: Alexandre Abrão
Quick stop device based on the shear-pin concept and with the impact of a hammer was developed by Yeo et al. (1992). It can be setup for experimental investigations. Deng et al. (2009) presented the typical examples of chip roots obtained with the QSD. Microstructure of machined chips from those materials was characterized by using optical and transmission electron microscopy. Barry and Byrne (2002) have found shear instabilities at the chip root, from observations made in quick-stop samples and truncated instabilities in the chip segments.

Childs (2006) investigated the nature of the friction contact between chip and tool during continuous chip formation using quick-stop experiments. QSD was used for development of a friction model. As stated by Sutter (2005), QSDs are very time consuming, there is a time delay in the tool retraction process, and the experimental arrangement of QSDs is fairly problematic. In this paper, the CAQSD was presented as an alternative to chip formation studies that employ QSDs.

Black and James (1980) have designed QSD for use in orthogonal machining and rubbing experiments. QSD's are used to obtain chip root samples that are representative of the deformation taking place during dynamic (actual) cutting conditions. Conventional and alternative quick stop devices have been frequently used for studying the chip formation mechanisms and the plastic deformation processes in shear zones and they have been reported by Griffiths (1986), Philip (1971), Satheesha et al. (1990), Vorm (1976) and Wager and Brown (1980). Moreover, different types of QSDs like electromagnetic quick stop device (EQSD) were designed by Wu et al. (2006). Furze et al. (1992) used the QSD for the wear analysis.

The goal of this study is focusing on what happens around the cutting edge when machining with rounded cutting edges. For this aim, CAQSD is presented as an alternative to the use of QSDs for the analysis of the dead metal zone formation and for its use in the improvement of mainly numerical machining models and the definition of equations. Cutting of workpiece was stopped automatically and abruptly by servo motor system. The abrupt stoppage leaves a chip root in the workpiece. The size of the stagnated workpiece material at the cutting edge was investigated by CAQSD with quick-stop tests. CAQSD was designed and manufactured for this work.

\section{Nomenclature}

$$
\begin{aligned}
& \mathrm{F}_{\mathrm{c}}=\text { cutting force } \\
& \mathrm{F}_{\mathrm{t}}=\text { thrust force } \\
& \mathrm{t} \quad \text { uncut chip thickness } \\
& \mathrm{V}_{\mathrm{c}}=\text { cutting speed }
\end{aligned}
$$


$\mathrm{r} \quad=$ cutting edge radius

$$
\begin{aligned}
& \text { Greek Symbols } \\
& \gamma \quad=\text { rake angle }
\end{aligned}
$$

\section{Computer Aided Quick-Stop Device (CAQSD)}

CAQSD is a research instrument developed for collecting the chip-root samples in shaping based machining. It is necessary to effectively freeze the cutting action without substantially disturbing the state of the chip. The chip root can then be accurately studied for various phenomena, such as the plastic deformation that occurs with chip separation in the metal cutting (Ozturk and Altan, 2012b).

The image of the CAQSD is given in Fig. 1. There are two basic motions in the device designed for this study. One of them is cutting and the other is sensitive depth cut motions. The maximum cutting speed of the CAQSD is $17.5 \mathrm{~m} / \mathrm{min}$. The maximum width and thickness of the chip that can be machined is respectively $1.5 \mathrm{~mm}$ and $2 \mathrm{~mm}$. A Mitutoyo 543-450 B digital dial gage is used to ensure parallelism of the work material and to provide the cutting depth. A servo drive from Control Techniques is used on a shaping based machining device for controlling the cutting speed and stopping distance of the single axis cutting. The servo motor drive applies power to the motor at different frequency ranges which are varied by the user. The CAQSD control system is designed providing accuracy and reliability without the need for an additional PLC. Cutting speed is determined easily by the software installed in the computer. Furthermore, cutting and thrust forces can be measured by single axis strain gages bonded to four facets of the tool during machining.

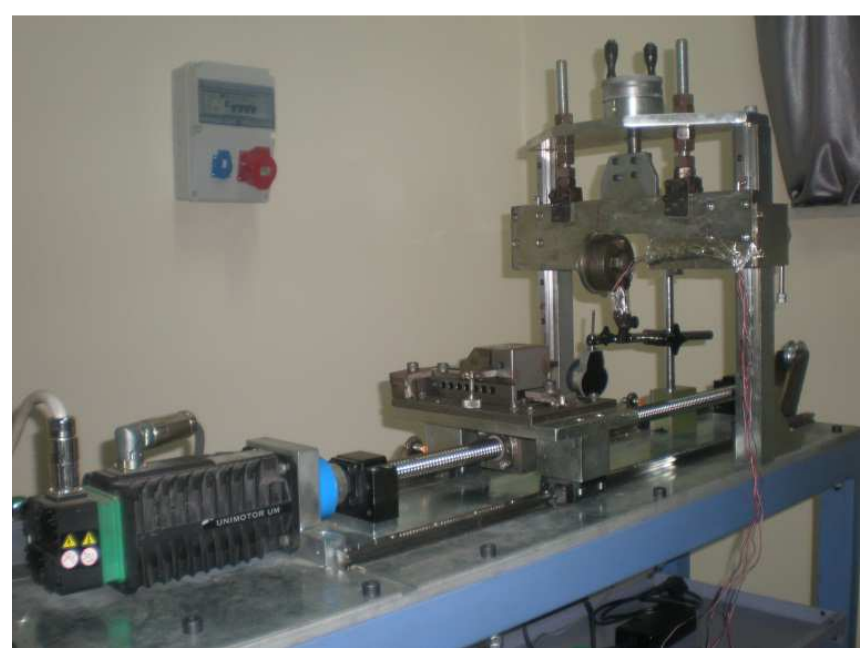

Figure 1. Computer Aided Quick-Stop Device (CAQSD).

A variety of quick stop devices are used to suddenly interrupt the cutting process. These devices change the relative velocity between the work material surface and the cutting tool to zero, to preserve the workpiece chip formation as accurately as possible.

Conventional quick stop devices provide rapid changes in relative velocity. In one of the type, a cutting tool is moved along a workpiece held by a shear pin. At a predetermined time, an explosive material is ignited and the forces generated break the shear pin and abruptly drive the cutting tool away from the work material. But this type of QSD works with mechanics and life of the device is limited with the pin broken. Some of the devices break the cutting tool, either mechanically or by using the force against the tool. Other devices combine the cutting force with a spring force to quickly move the tool away from the workpiece during cutting. This type, however, is subject to the relatively small spring and cutting forces, but showing insufficient acceleration of the tool relative to the workpiece.

The QSDs have some problems which include the relatively long time required and the difficulty involved with setting up the devices for experimentation and cutting. It is also difficult to adapt the quick stop designs to a variety of different cutting machines and tools. It can be desirable to use the QSDs with a variety of different machine tools and cutting conditions.

Some of the QSDs work for examining the metallurgical configuration of a longitudinal cut along a work material. However, the quick devices are inadequate for investigating the cutting of a work material. Assessments of the performance of the device in its general design revealed to have serious faults. These faults were rectified by modification of the quick-stop system.

Comparing the conventional quick stop devices and the CAQSD, the CAQSD has shown to have longer life, more safety, and less response time than the conventional one. We agreed on a skeleton of the device with the help of the FEM analysis. Finite element simulations yielded very good predictions in terms of forces and elastic strain analysis; however, deformation was underpredicted by the finite element software. The geometry and structure of the cutter holder is necessary for machining with the CAQSD. The performance of this device was analyzed and tested.

The present invention relates to works without an apparatus. The vice includes a mount adapted for attachment to the sample. The first sensor is a position sensor for the carriage parking and the other is for the emergency stop. The workpiece holder vice is fitted on the screw shaft and driven with servo motor. After the device starts working in the park position, then the carriage position is determined by the servo motor. The CAQSD should stop with the computer comment. If the CAQSD does not stop, then the sensor system will turn off the device.

\section{Cutting Parameters and Method}

\section{Materials and cutting parameters}

In the experiments brass workpiece material was used; chemical composition of the samples was as follows: $\mathrm{Cu} \%=69.809 ; \mathrm{Zn} \%=$ 30.138; $\mathrm{Sn} \%=0.0029 ; \mathrm{Pb} \%=0.005 ; \mathrm{Fe} \%=0.0219 ; \mathrm{P} \%=0.0019$. The hardness of the workpiece material was $70 \mathrm{HV}$. The dimensions of the supplied sample material were $32 \mathrm{~mm}$ x $30 \mathrm{~mm}$ x $1.5 \mathrm{~mm}$.

The workpiece material CuZn30 was shaped. Triangular inserts were described as follows: (1) TPGN 160308-005; (2) TPGN 160308-010; (3) TPGN 160308-015 and relief angles custom manufactured by a tool company. The cutting insert was mounted on the tool holder by mechanical tightening. The edge radius values were 50,100 , and $150 \mu \mathrm{m}$. Cutting speed of $0.25,0.5$, and 0.75 $\mathrm{m} / \mathrm{min}$ were used in the tests. The experiments were conducted for different uncut chip thickness rates of 50,100, and $150 \mu \mathrm{m}$. Cutting fluid was not used during the tests. The cutting forces were measured during the experiments.

\section{Experimental method}

Orthogonal cutting tests were conducted in order to verify the formation of the dead metal zone. Relief angle of cutting tool inserts was 11 degrees. The cutting edge radii have been measured using a two-dimensional profilometer with a high sensitivity. The cutting tool bonded on the tool holder by mechanical compression. The uncertainties of the measurements were lower than $1 \mu \mathrm{m}$. Stopping distance of the single plane cutting motion could be adjusted with the PLC program software. The time taken during the toolworkpiece separation process should be as small as possible. We carefully avoided temperature effect. At these speeds temperature effects are likely to be negligible. In order to eliminate the effect of 
high freezing time, a small value of stop freeze time was chosen. Freezing time was selected $0.001 \mathrm{~s}$. Response time of the device was very short. This is the main advantage of the CAQSD. Response time is much better than the other conventional equipment.

The procedures of the experiments can be summarized as follows: (1) preparations of workpiece and cutting triangular inserts (2) setting of the cutting velocity and quick stop distance with software; (3) cutting with CAQSD; (4) freezing the cutting action automatically; (5) grinding and polishing the samples; (6) etching the polished surface; (7) analyzing the specimen. The samples were examined under optical microscope. Only continuous chip formation was studied; this ensured constant force values during steady-state cutting.

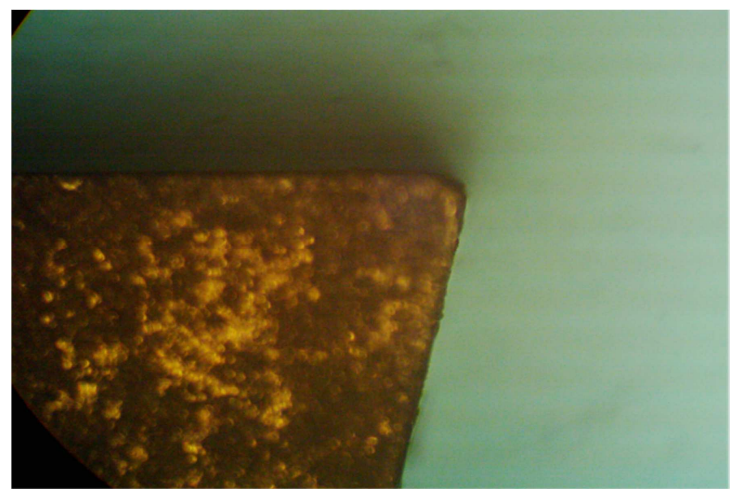

Figure 2. Photomicrograph of a new cutting insert edge at $100 \times$ magnification $(r=100 \mu \mathrm{m})$.

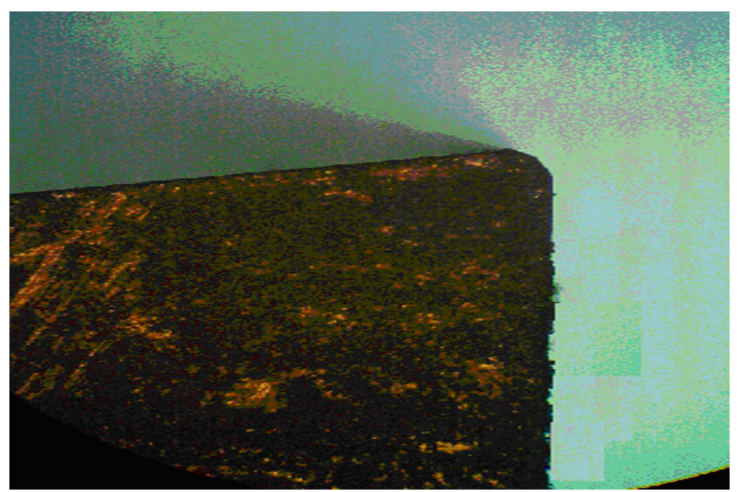

Figure 3. Photomicrograph of a new cutting insert edge used for once at $100 \times$ magnification $(r=100 \mu \mathrm{m})$.

We used the cutting insert in the cutting action freezing only once to avoid distortion on the cutting edge. A new cutting insert edge is given in Fig. 2. After the metal cutting operation at the cutting parameters $\mathrm{r}=100 \mu \mathrm{m}, \mathrm{t}=150 \mu \mathrm{m}$, and $\mathrm{V}_{\mathrm{c}}=0.5 \mathrm{~m} / \mathrm{min}$ profile of the cutting edge was not distorted by the freezing process, as shown in Fig. 3. Because wire erosion offers superior repeatability and consistency, examination of the cutting insert edge geometry was performed by wire erosion. The sample illustrated in Fig. 3 was obtained parallel with the cutting edge. A distortion has not appeared in this insert. Nevertheless, cutting tool inserts were used once per one metal cutting operation. Consequently, when the new cutting inserts are used, dead metal zone can be seen clearly.

\section{Results and Discussions}

It is observed from experimental result that the uncut chip thickness and cutting edge radius have significant effect on cutting force. In addition, the interaction of dead metal zone and cutting edge radius is also significant. In the beginning of the cutting process, the stagnation zone started to form, and then its size stabilized when steady state cutting was reached. A small dead region is seen in front of the rake face of tool during cutting with rounded edge tool (Ozturk and Altan, 2012a).

Chip roots obtained through micrograph images are shown in Figs. 4-7. Figures 4-7 demonstrate the stagnation point position on the tool tip at different cutting velocity. The stagnated region is almost a part of a circle in shape, and the area of the zone increased with edge radius. It is expressed that dead region existed and built up edge did not come into being at machining with brass

It is important to note that the dead metal zone phenomenon is considered in these figures. This study considers the existence of dead metal zone. The increase in plastic deformation with tool-edge radius can be explained in terms of the formed dead-metal zone. A dead metal zone is clearly observed when using edge radiused tools. Moreover, it is obvious from these images that as edge radius increases, dead metal zone size increases. Possible reasons for this increase may be due to the enlargement of plastic deformation zone as edge radius decreased. Subsequently, stagnant dead-metal zone covers greater range of the tool tip in all cutting cases as shown in Figs. 4-7.

Photomicrograph of chip roots obtained at the cutting parameters $r=$ $100 \mu \mathrm{m}$ and $\mathrm{t}=50 \mu \mathrm{m}$ is shown in Fig. 4. The dead metal zone formation is obvious from this image.

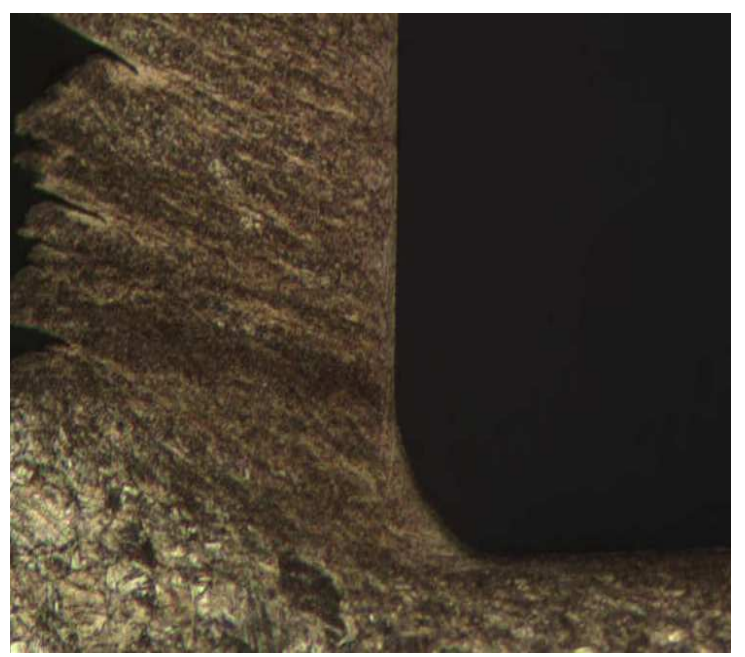

Figure 4. Photomicrograph of samples at $100 \times$ magnification (CuZn30, $\mathrm{Y}=$ $\left.0^{\circ}, r=100 \mu \mathrm{m}, V_{c}=0.75 \mathrm{~m} / \mathrm{min}, \mathrm{t}=50 \mu \mathrm{m}\right)$.

Figure 5 illustrates the dead metal formation at the cutting parameters $\mathrm{r}=100 \mu \mathrm{m}$ and $\mathrm{t}=100 \mu \mathrm{m}$. Material below the stagnation point is compressed by the rounded cutting edge to form the machined surface while material above the stagnation point is separated as chips. For many photomicrographs it is clear that the material removed as a chip was restricted within the zone which was in front of the dead metal zone. Thus dead metal zone plays an important role in the chip formation. 


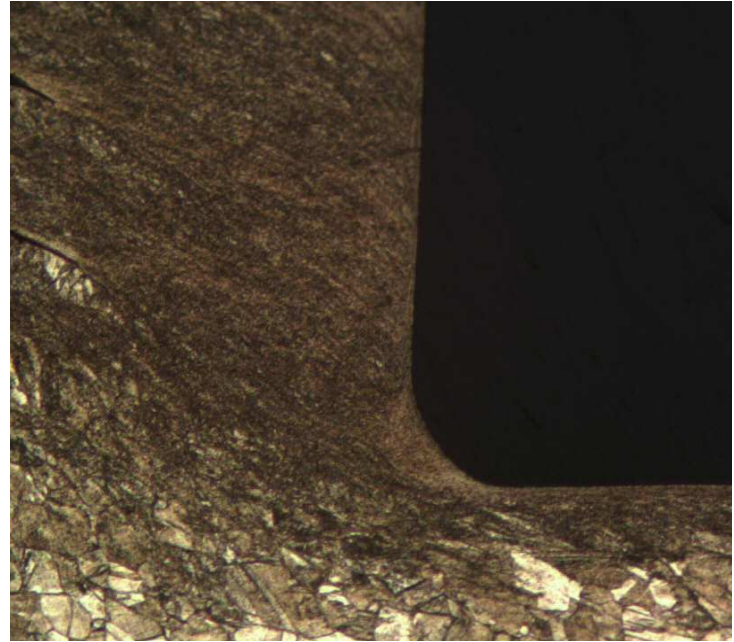

Figure 5. Photomicrograph of samples at $100 \times$ magnification $(\mathrm{CuZn30,} \mathrm{y}=$ $\left.0^{\circ}, \mathrm{r}=100 \mu \mathrm{m}, \mathrm{V}_{\mathrm{c}}=0.25 \mathrm{~m} / \mathrm{min}, \mathrm{t}=100 \mu \mathrm{m}\right)$.

In Fig. 6, dead metal zone can be seen under the cutting parameters $\mathrm{r}=100 \mu \mathrm{m}$ and $\mathrm{t}=150 \mu \mathrm{m}$. On the stagnation zone, grain size is completely changed. Grain boundaries could not be seen at the dead metal zone and chip formation area. It can be clearly seen that dead metal zone exists and built up edge does not generate during machining with brass.

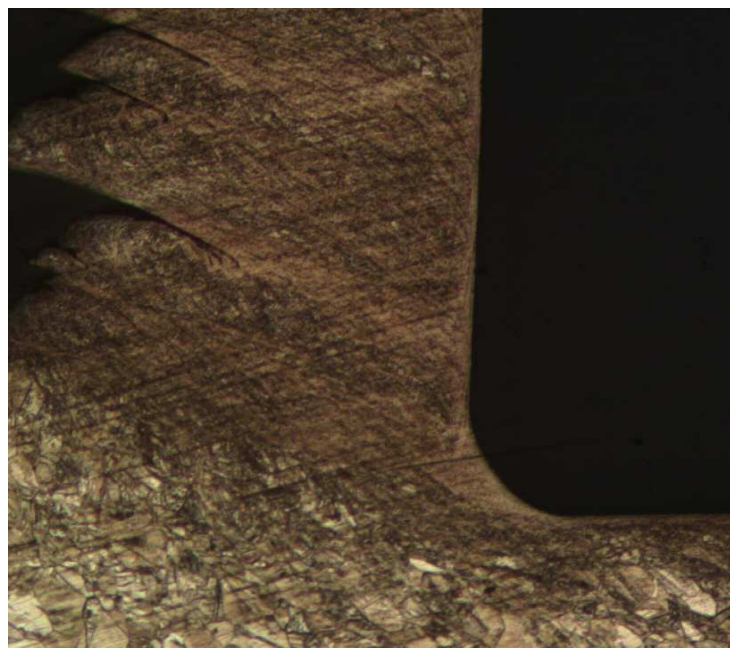

Figure 6. Photomicrograph of samples at $100 \times$ magnification (CuZn30, $\mathrm{Y}=$ $\left.0^{\circ}, \mathrm{r}=100 \mu \mathrm{m}, \mathrm{V}_{\mathrm{c}}=0.75 \mathrm{~m} / \mathrm{min}, \mathrm{t}=150 \mu \mathrm{m}\right)$.

Dead metal zone can be seen under the cutting parameters $r=$ $150 \mu \mathrm{m}$ and $\mathrm{t}=150 \mu \mathrm{m}$, in Fig. 7. To the photomicrograph of cross section of the cutting zone, a small zone can be seen directly on the tool. Dead metal zone enlarges as the cutting speed decreases. Due to the fact that increase of this distance is too small, effect of the cutting speed on the process is negligible.

It is clear from the experimental results that, as edge radius increases, area of the dead metal zone increases. Also changes in $\mathrm{F}_{t}$ (thrust force) and $F_{c}$ (cutting force) were measured by using quick stop device for various cutting speeds and $\mathrm{CuZn} 30$ work material, and at a range of edge radius $50-150 \mu \mathrm{m}$. Although cutting speeds exercised in this study are lower than the speeds normally used in metal cutting, a small value of freezing time was selected as $0.001 \mathrm{~s}$ to eliminate the effect of lower cutting speeds. Consequently it appears that the formation of the chip will be similar to that in the machining. The clear images of the dead metal zone are the further proof of this conjecture. Nevertheless, it would be useful in future experiments to attempt to study dead metal zone formation at high speeds. Increasing cutting edge radius increases the cutting force. Moreover, the effect of rake angle on cutting forces becomes more noticeable when the edge radius increases.

It can be seen from the photomicrographs presented in this work that the CAQSD can be used as a research instrument for the study of chip formation for all the samples to be cut.

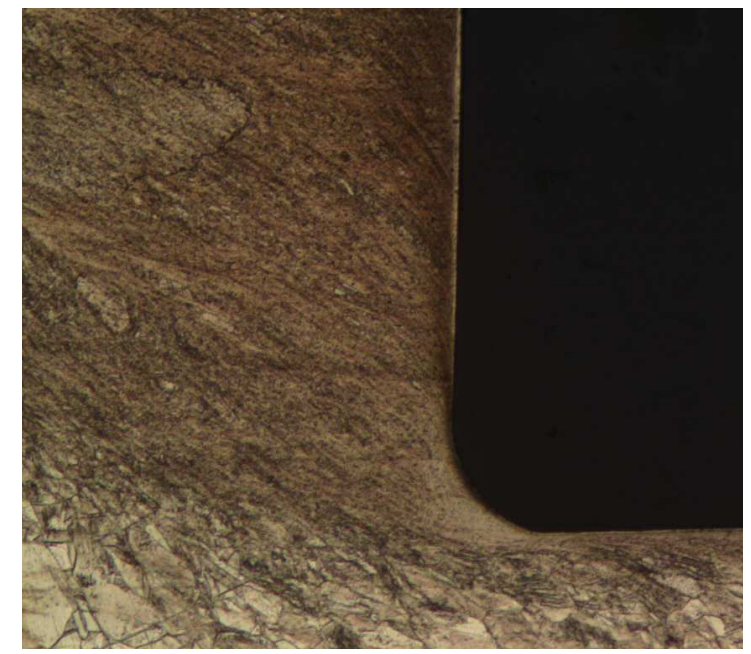

Figure 7. Photomicrograph of samples at $100 \times$ magnification $(\mathrm{CuZn30,} y=$ $\left.0^{\circ}, \mathrm{r}=150 \mu \mathrm{m}, \mathrm{V}_{\mathrm{c}}=0.5 \mathrm{~m} / \mathrm{min}, \mathrm{t}=150 \mu \mathrm{m}\right)$.

\section{Conclusion}

The paper describes the development of a new computer aided quick-stop device (CAQSD) for metal cutting research. The results showed that the CAQSD meets much better performance than requirement of conventional quick stop device. Operation of the device is very simple and CAQSD has been found to give reliable performance. The design consideration of the CAQSD elements was explained. All parts of the device were analyzed by FEM software package, ANSYS ${ }^{\circledR}$ Workbench $^{\mathrm{TM}}$. A new type tool holder was designed and manufactured.

One prospect of the metal cutting research is primarily concerned with the activity occurring between the work material and the cutting edge of the tool. It can be seen from the photomicrographs that the new device can be applied easily as a research instrument for the study of chip formation. For instance, it is often necessary to study the contact zone between the cutting tool and the chip root. The present invention solves the drawbacks of the conventional quick stop devices. It was demonstrated through experiments that edge radius of the cutting tool affects the machining and dead metal zone.

\section{Acknowledgements}

The authors would like to thank the Yildız Technical University's Scientific Research Projects Coordination Department for the financial funding for this project (No: 25-06-01-02).

\section{References}

Barry, J. and Byrne, G., 2002, "The mechanisms of chip formation in machining hardened steels", Journal of Manufacturing Science and Engineering, Vol. 124, pp. 528-535. 
Black, J.T. and James, C.R., 1980, "Hammer qsd-quick stop device for high speed machining and rubbing", American Society of Mechanical Engineers, (Paper) 80, wa/prod-13.

Buda J., 1972, "New methods in the study of plastic deformation in the cutting zone", Annals of CIRP, Vol. 21, pp. 17-18.

Chern, G.L., 2005, "Development of a new and simple quick-stop device for the study on chip formation", International Journal of Machine Tools \& Manufacture, Vol. 45, pp. 789-794.

Childs, T.H.C., 2006, "Friction modelling in metal cutting", Wear, Vol 260(3), pp. 310-318.

Deng, W.J., Xia, W., Li, C. and Tang, Y., 2009, "Formation of ultra-fine grained materials by machining and the characteristics of the deformation fields", Journal of Materials Processing Technology, Vol. 209, pp. 4521-4526.

Furze, D.C., Griffiths, B.J. and Carrey, M.C., 1992, "Wear analysis using a quick stop device", Journal of Tribology, Vol. 114, pp. 524-529.

Griffiths, B.J., 1986, "Development of a quick-stop device for use in metal cutting hole manufacturing processes", International Journal of Machine Tool Design \& Research, Vol. 26, pp. 191-203.

Jaspers, S.P.F.C. and Dautzenberg, J.H., 2002, "Material behaviour in metal cutting: strains, strain rates and temperature in chip formation", Journal of Materials Processing Technology, Vol. 43, pp. 1-13.

Komanduri, R., 1971, "Some aspects of machining with negative rake tools simulating grinding", International Journal of Machine Tool Design \& Research, Vol. 11, pp. 223-233.
Ozturk, S. and Altan, E., 2012a. "A slip-line approach to the machining with rounded-edge tool", The International Journal of Advanced Manufacturing Technology, Vol. 36, pp. 513-522.

Ozturk, S. and Altan, E., 2012b. "Slip-Line Metal Cutting Model with Negative Rake Angle", Journal of the Brazilian Society of Mechanical Sciences and Engineering, Vol. 34, No. 3, pp. 246-252.

Philip, P.K., 1971, "Study of the performance characteristics of an explosive quick-stop device for freezing cutting action", International Journal of Machine Tool Design \& Research, Vol. 11, pp. 133-144.

Satheesha, M., Jain, V.K. and Kumar, P., 1990, "Design and development of a quick-stop device (QSD)", Precision Engineering, Vol. 12, pp. 205-212

Sutter, G., 2005, "Chip geometries during high-speed machining for orthogonal cutting conditions", International Journal of Machine Tools \& Manufacture, Vol. 45, pp. 719-726.

Vorm, T., 1976, "Development of a quick-stop device and an analysis of the frozen-chip technique”, International Journal of Machine Tool Design \& Research, Vol. 16, pp. 241-250.

Wager, J.G. and Brown, R.H., 1980, "New quick-stop device for milling and grinding", CIRP Annals - Manufacturing Technology, Vol. 29, pp. 15-18.

Wu, C.L., Wang, K.S. and Tsai, L.C., 2006, "New electromagnetic quick stop device for metal cutting studies", International Journal of Advanced Manufacturing Technology, Vol. 29, pp. 853-859.

Yeo, S.H., Lui, W.W. and Phung, V., 1992. "A quick-stop device for orthogonal machining", Journal of Materials Processing Technology, Vol. 29, pp. 41-46. 